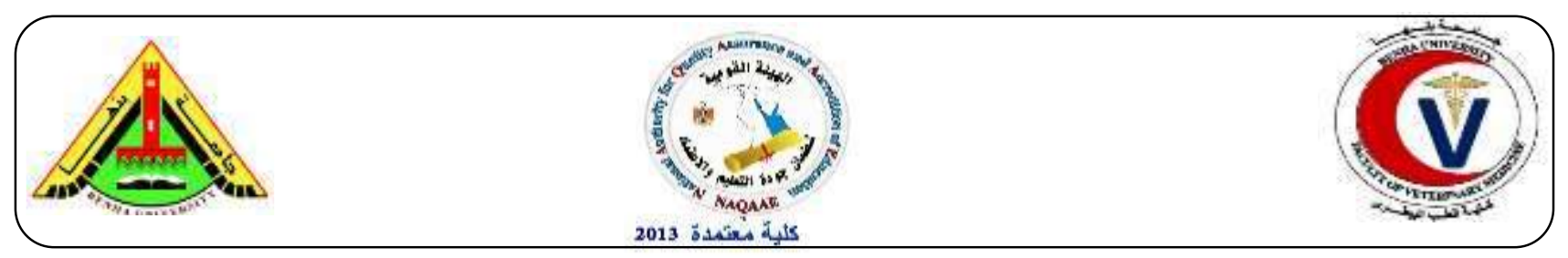

\title{
Detection of Leptospira in cattle and dogs in Dakahlia Governorate
}

\author{
Gihad I. Towheed ${ }^{1}$, Samar M.M. Atwa ${ }^{1}$, Eisa M. I. M. ${ }^{2}$, Omnia F. H. Badawy ${ }^{3}$, Saad M. Mohamed ${ }^{4}$, \\ Elzahraa K. Elbaz ${ }^{1}$ and Elbeskawy Mohamed ${ }^{5}$ \\ ${ }^{1}$ Department of Internal Medicine \& Infectious and Fish Diseases, Faculty of Veterinary Medicine, Mansoura \\ University \\ ${ }^{2}$ Department of Animal Medicine, Faculty of Veterinary Medicine, Zagazig University \\ ${ }^{3}$ Department of Bacteriology, Animal Health Research Institute, Dokki, Giza \\ ${ }^{4}$ Animal Reproduction Research Institute, Al-Haram, Giza, Egypt. \\ ${ }^{5}$ Department of Animal Medicine, Faculty of Veterinary Medicine, Matrouh University
}

\section{A B S T R A C T}

This study was done to investigate the infection rates of leptospirosis in different Veterinary Clinics in Dakahlia Province during the period from September 2016 to December 2017, The study was applied on a total of 115 urine samples, collected from suspected cattle (97) and their in-contact dogs (18), which suffered from different clinical signs of leptospirosis. The collected samples were examined for Leptospira spp. by different methods as Dark Field Microscopy (DFM) and staining by Silver Impregnation Method "Fontana Method". The results of DFM showed that, 28 out of 97 (28.9\%) cattle urine samples were positive, and eight out of $18(44.4 \%)$ dogs' urine samples were positive. Additionally, the results of Fontana Method revealed that, 44 out of $97(45.4 \%)$ cattle urine samples were positive, and 13 out of 18 (72.2\%) dogs' urine samples were positive. To confirm these results, conventional polymerase chain reaction (PCR) targeting (23S rDNA) gene of Leptospira, was done on 6 urine samples, included 3 cattle urine samples and 3 dogs' urine samples (one sample was positive, and two samples were negative in each species). PCR result confirmed the DFM and Fontana method results. In addition, a treatment trial for three groups of cattle infected with leptospirosis was performed by Dihydrostreptomycin, Oxytetracycline and Amoxicillin, respectively for 3 days. This study showed higher prevalence of leptospirosis in Dakahlia by DFM and Fontana methods. Moreover, Dihydrostreptomycin, Oxytetracycline and Amoxicillin have been successfully affecting on leptospirosis.

Keywords: DFM, Fontana, Leptospirosis, PCR.

\section{INTRODUCTION}

Leptospirosis is an infectious, waterborne and zoonotic disease caused by bacteria called Leptospira which affects domestic, wild animals and human (Quinn et al., 2011).
Leptospira is long, thin, highly motile, spiralshaped bacteria (Klaasen and Adler, 2015). The genus Leptospira is grouped into 2 species. The pathogenic species "interrogans" 
which causes leptospirosis, and the nonpathogenic species "biflexa" (Dehkordi et al., 2011). The most common pathogenic serovars are hardjo, pomona, canicola, icterohaemorrhagiae and grippotyphosa (Carmona-Gasca et al., 2011).

The economic losses in the cattle industry caused by leptospirosis include, drop in the milk production, mastitis, abortion, infertility and death of young calves (Shafighi et al., 2010).

Leptospirosis is a seasonal disease. Its outbreak occurs in rainy season and after floods (Safiullah et al., 2009). Leptospirosis is transmitted to human through direct contact with urine of carrier animals, rodents or dogs or through contact with damp soil contaminated with urine (Goarant, 2016).

Leptospiral infection in cattle is associated with infertility, early embryonic death and abortion during the last trimester of pregnancy (Grooms, 2006).

Leptospirosis in dogs is manifested by fever, muscular stiffness, jaundice, vomiting, diarrhea, acute renal failure, conjunctivitis, abortion, and death (Sykes et al., 2011; Ellis, 2015).

Many authors evaluated the detection of Leptospira spp. in cattle and dogs in urine by DFM (Krishna et al., 2012; Salgado et al., 2015; Saritha et al., 2016), by Fontana Method (Lather et al., 2009; Ajaj and Farwachi, 2013) and PCR (Yesilmen et al., 2012; Nandini et al., 2014; Pinna et al., 2018) .

DFM is a cost effective, simple, reliable and rapid test, which can be used as an important tool for the early diagnosis of leptospirosis (Saritha et al., 2016). However, DFM has some drawbacks which include lack of sensitivity and specificity, due to the presence of some artifacts like serum proteins and cell fragments which may be mistaken with Leptospira (Klaasen and Adler, 2015). Moreover, Leptospira is excreted intermittently in the urine and the concentration of the organism may be too low at the time of collection (Budihal and Perwez, 2014). Approximately, $10^{4}$ Leptospira $/ \mathrm{ml}$ are necessary for one cell per field to be visible by DFM (Mythri, 2015). Leptospira is thin and spiral bacteria, which cannot be stained by the Gram stain. Silver Impregnation Method "Fontana Method" is used for staining smears by deposition of silver on Leptospira, which leads to increase its thickness, and then Leptospira can be demonstrated by light microscopy as brownish black organisms against yellow background (Gunasekara et al., 2017; Lather et al., 2009; Rodríguez et al., 2013). Fontana Method is a relatively inexpensive method, the stained bacteria can be observed by using the ordinary light microscope, which is available in a basic laboratory setting (Gunasekara et al., 2017). However, Fontana Method may have some drawbacks such as lack of sensitivity with a high risk for false-positive and false-negative results (Klaasen and Adler, 2015).

PCR is an important diagnostic test which offers a rapid alternative to culture for the diagnosis of slow growing or fastidious microorganisms such as Leptospira in different biological samples such as urine, serum and organs (Pinna et al., 2018). PCR amplifies as few number of Leptospira as 10 bacteria/ $\mathrm{ml}$, it is faster, more sensitive and more specific than DFM (Nandini et al., 2014).

This work aimed to study the clinical signs of leptospirosis in cattle and their in-contact dogs in Dakahlia Province, to diagnose leptospirosis in cattle and dogs by DFM and Fontana method, to confirm the results by PCR and finally to detect the effect of several antibiotics on leptospirosis in diseased cattle.

\section{Materials and methods}

\subsection{Animals: \\ Cattle:}

Ninety-seven suspected female cattle were examined in this study from different 
Veterinary Clinics in Dakahlia Province during the period from September 2016 to December 2017 (Table 1). Twenty-nine cattle were less than three years old; 65 cattle had age ranged from three to five years, while 3 cattle had more than 5 years (Table 2). They were clinically examined according to (Constable et al., 2017).

Dogs:

Eighteen suspected dogs (12 adults, 6 puppies) (Table 3) from the same localities of cattle were collected during August and September in 2017, they were examined according to (Kelly, 1986).

\subsection{Urine samples collection and preparation:}

Urine from cattle was collected by catheters, while from dogs by sterile syringes from urinary bladder.

The urine samples of cattle and dogs were centrifuged. The sediment was transferred in sterile screw capped bottles contained transport media, which consists of phosphate buffer saline, rabbit serum 5\% and 5-FLU 1:100000 for propagation of Leptospira and killing other bacteria. The bottles were sent to the laboratory, kept in the dark at room temperature $\left(28^{\circ} \mathrm{C}\right)$ until examination by DFM.

2.3. Microscopic examination of urine samples:

The collected urine samples were examined by DFM \& Fontana method at Bacteriology Department, Animal Health Research Institute, Dokki, Giza.

\section{A-DFM:}

Small drops of urine from each bottle were placed on clean slide and examined with DFM (Sakhaee et al., 2007).

\section{B- Fontana Method:}

A smear from urine sample was prepared on a clean glass slide, allow to air dry. It was treated with Fontana's Fixative (Acetic Acid 1\% and Formalin 2\%) three times each for 30 seconds. The slide was rinsed with absolute ethyl alcohol and allowed to react for 3 minutes, drained the excess ethyl alcohol and leaved the slide to dry. The smear was flooded with Fontana's Mordant (phenol 1\% and Tannic Acid 5\%). The slide was heated until steam rises and the smear became brown in color. The smear was treated with Fontana's stain (Silver Nitrate 5\%). The smear was washed with distilled water. It was allowed to dry and examined by ordinary microscope (Greene et al., 1998).

2.4. Molecular detection of leptospirosis:

The PCR assay was done at Animal Health Research Institute, Mycoplasma Department, Molecular Unit.

\section{DNA extraction:}

The DNA was extracted from urine samples by Patho Gene-Spin ${ }^{\mathrm{TM}}$ DNA/RNA Extraction kit manufactured by iNtRON Biotechnology, Korea. The DNA was stored at $-20^{\circ} \mathrm{C}$ until used in PCR.

2. Conventional polymerase chain reaction:

Conventional PCR targeting the gene (23S rDNA) of Leptospira was performed by Thermo Scientific Dream Taq Green PCR Master Mix (2X) manufactured by Thermo Fisher Scientific Inc., USA. The primer pair L737 Forward (5'GACCCGAAGCCTGTCGAG3') and L1218 Reverse (5'GCCATGCTTAGTCCCGATTAC 3')

(Woo et al., 1997), were synthesized by Sigma Company, (Germany), to amplify a $482 \mathrm{bp}$ fragment. DNA samples were tested in $50 \mu 1$ reaction volumes in a $0.2 \mathrm{ml}$ eppendorf tube, containing $25 \mu \mathrm{l}$ PCR Mix that was composed of: (10X buffer, 10mM d NTPs mixture, Taq polymerase), $1 \mu$ l of each primers, $2 \mu 1$ target DNA, complete to a final volume of $50 \mu$ with sterile molecular water.

PCR amplification conditions consisted of: A denaturation step of 30 cycles at $94^{\circ} \mathrm{C}$ for 20 seconds, an annealing step of 30 cycles at $54^{\circ} \mathrm{C}$ for 30 seconds, an extension step of 30 cycles at $72^{\circ} \mathrm{C}$ for 1 minute and final extension step of one cycle at $72^{\circ} \mathrm{C}$ for 6 minutes. PCR 
products were analyzed for the presence of specific fragments of the expected length in a $1.5 \%$ agarose gel electrophoresis stained with Ethidium bromide (Brown et al. 1995) and visualized by ultraviolet transillumination.

\subsection{Trials for treatment of diseased cattle:}

Fifteen diseased cattle from Veterinary Clinics, which showed signs of leptospirosis and have not received previous treatment, were divided into 3 groups, (Five cattle in each group) and treated as following:

First group: injected intramuscularly with Dihydrostreptomycin (10 mg/kg BW) every 24 hours for 5 days.

Second group: injected intramuscularly with Oxytetracycline LA, (1 ml/10kg BW), dose was repeated after 48 hours.

Third group: injected intramuscularly with Amoxicillin (1 ml/10kg BW), dose was repeated after 48 hours. Cattle in all groups received symptomatic and supportive treatment.

\section{RESULTS}

\subsection{Clinical findings:}

In cattle:

The clinical examination of 97 female cattle, showed different clinical signs such as fever which ranged from $39-40.5^{\circ} \mathrm{C}$ in $13(13.4 \%)$ cattle, abortion in $62(63.9 \%)$ cattle, infertility (repeat breeding) in $4(4.1 \%)$ cattle, mastitis in $35(36.1 \%)$ cattle, milk drop (without mastitis) in $6(6.2 \%)$ cattle, bloody milk in $5(5.2 \%)$ cattle and flakes in milk in $1(1.0 \%)$ cattle (Table 4).

In dogs:

The clinical examination of 18 dogs (12 adults and 6 puppies), showed different clinical signs including, fever which ranged from 39.5$40.5^{\circ} \mathrm{C}$ and dyspnea in puppies, while adults showed fever, depression, stiff gait, reluctant move, sunken eyes, jaundice and bloody salivation (Table 5).

\subsection{Laboratory diagnosis:}

\section{1- DFM:}

Leptospires were detected in 28 out of 97 (28.9\%) cattle urine samples (Table 6). In dogs, Leptospires were detected in 6 out of 12 $(50.0 \%)$ and 2 out of $6(33.3 \%)$ urine samples of adults and puppies, respectively (Table 7). The total number of positive dogs' urine samples was 8 out of 18 (44.4\%). Leptospires appeared under DFM as long, tightly coiled, and rapidly rotated spirochetes with characteristic hook ends.

\section{2- Fontana Method:}

Leptospires were detected in 44 out of 97 (45.4\%) cattle urine samples (Table 8), whereas in dogs, Leptospires were detected in 10 out of $12(83.3 \%)$ and 3 out of $6(50.0 \%)$ urine samples of adult dogs and puppies, respectively (Table 9). The total No. of positive dogs' urine samples was 13 out of 18 (72.2\%). Leptospira appeared in silver stained urine smear under ordinary microscope as brownish black spirochaetes against yellow background (Figs.1 and 2).

\section{3- PCR:}

Three cattle and three dogs' urine samples were subjected to PCR for confirmation of the results of DFM and Fontana Method. The 3cattle' urine samples include one positive sample by DFM and Fontana Method and 2 negative samples, and the 3 dogs' urine samples were the same as cattle.

Leptospiral fragments of size 482 bp were detected in one cattle urine sample (Lane 2) and in one dog urine sample (Lane 5), they were positive previously by DFM and Fontana Method. While the other two cattle urine samples (Lane 3, 4) and two dogs' urine samples (Lane 6,7) were negative by PCR, which were negative by DFM and Fontana Method (Fig.3).

\subsection{Treatment trials of diseased cattle:}


The treated cattle showed health improvement and returned to normal activity from the second day of treatment with Dihydrostreptomycin, Oxytetracycline and Amoxicillin.

Table1: Classification of cattle according to month of collection.

\begin{tabular}{llc}
\hline Year & Month & Number of samples \\
\hline 2016 & September & 26 \\
& July & 6 \\
& August & 24 \\
2017 & September & 15 \\
& October & 12 \\
& November & 2 \\
& December & 12 \\
& & 97 \\
\hline
\end{tabular}

Table 2: Classification of cattle according to localities and age.

\begin{tabular}{lcc}
\hline Localities & Age & Total \\
\hline \multirow{2}{*}{ Veterinary Clinics } & $<3$ years & 29 \\
& $3-5$ years & 65 \\
Total & $>5$ years & 3 \\
\hline
\end{tabular}

Table 3: Classification of dogs according to age and Sex.

\begin{tabular}{llrrr}
\hline & Age & \multicolumn{2}{c}{ Sex } & \multirow{2}{*}{ Total } \\
\cline { 3 - 4 } Dogs & Male & Female & \\
\hline Adults & 6 months -5 years & 9 & 3 & 12 \\
Puppies & $\leq 6$ months & 4 & 2 & 6 \\
Total & & 13 & 5 & 18 \\
\hline
\end{tabular}


Table 4: Cattle with clinical signs of leptospirosis.

\begin{tabular}{lll}
\hline \multirow{2}{*}{ Clinical findings } & \multicolumn{2}{l}{ Cattle from Veterinary Clinics (97) } \\
\cline { 2 - 3 } & Number & Percentage \\
\hline Fever & 13 & $13.4 \%$ \\
Abortion & 62 & $63.9 \%$ \\
Infertility & 4 & $4.1 \%$ \\
Mastitis & 35 & $36.1 \%$ \\
Drop in milk production & 6 & $6.2 \%$ \\
Flakes in milk & 1 & $1.0 \%$ \\
Bloody milk & 5 & $5.2 \%$ \\
\hline
\end{tabular}

Table 5: Clinical findings on dogs.

\begin{tabular}{ccc}
\hline Clinical Findings & Puppies & Adults \\
\hline Fever & + & + \\
Stiff gait & - & + \\
Sunken eyes & - & + \\
Bloody salivation & - & + \\
Jaundice & - & - \\
Respiratory disorders & + & + \\
\hline
\end{tabular}

Table 6: Results of DFM on cattle urine samples.

\begin{tabular}{ccccc}
\hline Total & $\begin{array}{c}\text { Number of } \\
\text { Positive }\end{array}$ & Positive \% & $\begin{array}{c}\text { Number of } \\
\text { Negative }\end{array}$ & Negative \% \\
\hline 97 & 28 & $28.9 \%$ & 69 & $71.1 \%$ \\
\hline
\end{tabular}

Table 7: Results of DFM on dogs' urine samples.

\begin{tabular}{llcc}
\hline & Total & Number of positive & Percentage \\
\hline Adults & 12 & 6 & $50.0 \%$ \\
Puppies & 6 & 2 & $33.3 \%$ \\
Total & 18 & 8 & $44.4 \%$ \\
\hline
\end{tabular}

Table 8: Results of Fontana Method on cattle urine samples.

\begin{tabular}{ccccc}
\hline Total & $\begin{array}{c}\text { Number of } \\
\text { Positive }\end{array}$ & Positive \% & $\begin{array}{c}\text { Number of } \\
\text { Negative }\end{array}$ & Negative \% \\
\hline 97 & 44 & $45.4 \%$ & 53 & $54.6 \%$ \\
\hline
\end{tabular}


Table 9: Results of Fontana Method on dogs' urine samples.

\begin{tabular}{llcc}
\hline & Total & $\begin{array}{c}\text { Number of } \\
\text { positive }\end{array}$ & Percentage \\
\hline Adults & 12 & 10 & $83.3 \%$ \\
Puppies & 6 & 3 & $50.0 \%$ \\
Total & 18 & 13 & $72.2 \%$ \\
\hline
\end{tabular}

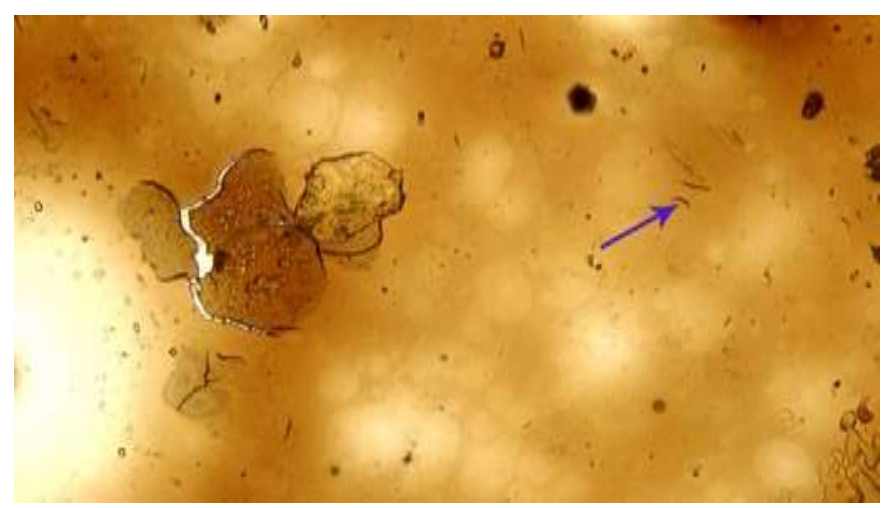

Fig.1. Leptospires appeared in silver stained urine smear by 100X magnification.

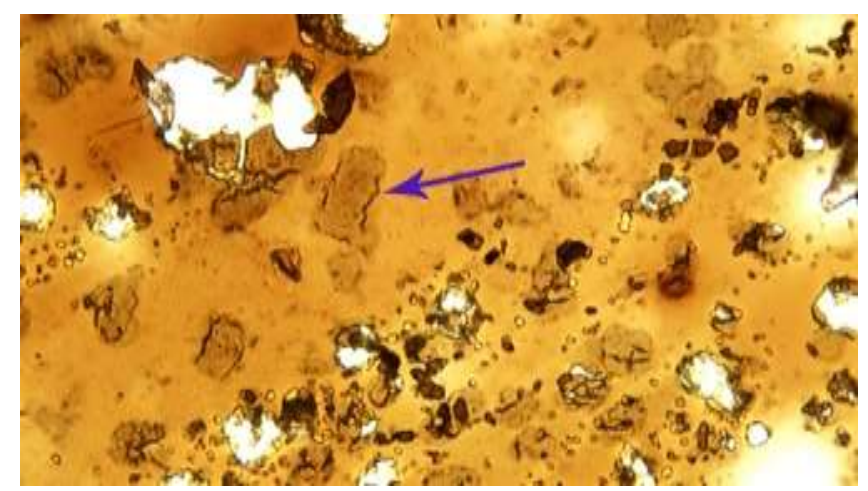

Fig.2. Leptospires appeared in silver stained urine smear by $100 \mathrm{X}$ magnification.

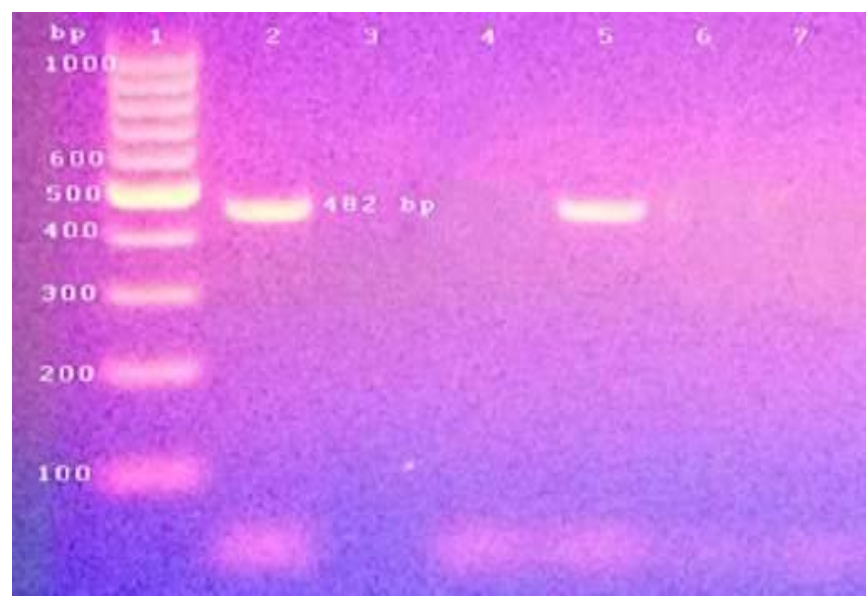

Fig.3. 1.5\% of agarose gel electrophoresis of PCR products stained with Ethidium bromide. L: Molecular weight DNA Ladder 


\section{DISCUSSION}

Leptospirosis is an infectious, zoonotic, waterborne disease, which is distributed worldwide (Dehkordi et al., 2011). It is transmitted mainly through urine of diseased or carrier animals (Ellis, 2015). Leptospirosis causes great economic losses such as abortions, infertility, stillbirth, weak offspring, drop in milk production and mastitis (Shafighi et al., 2010).

In this study, urine samples were collected from cattle with clinical signs of leptospirosis such as fever, abortion in the last stage of pregnancy, infertility, mastitis, bloody milk, flakes in milk and milk drop. These signs are in agreement with that observed previously by (Badran et al., 2010).

In dogs, the adults showed fever, weakness, stiff gait, reluctant movement, sunken eyes, salivation and jaundice while puppies showed fever and dyspnea. Similar clinical signs were reported by many authors (Lather et al., 2009; Romero-Vivas et al., 2013).

The infection rate recorded in cattle' urine samples by DFM was (28.9\%). This ratio was recorded by (Hernández-Rodríguez et al., 2011). The succes of DFM depends on the presence of a large number of Leptospires in the urine during collection (Sakhaee et al., 2007).

In contrast, a study detects Leptospires in $(0.72 \%)$ cattle urine samples by DFM, and concludes that DFM is unreliable, underestimates the actual percentage of diseased or carrier cattle, has lower sensitivity and specificity, requires a laboratory near the collection site (Zacarias et al., 2008).

In dogs, the infection rate was $(50.0 \%)$ in adults, and (33.3\%) in puppies by DFM. The total infection rate in dogs was (44.4\%). This is in agreement with a study by (Krishna et al., 2012).

The infection rate here, was higher in adults than puppies, due to exposure of adult dogs to multiple infection sources than puppies such as scavenging garbage, hunting for food, drinking contaminated water (Nandini et al., 2014). Leptospira usually affects adult dogs whose age ranges from one to six years (Saritha et al., 2016).

In contrast, one dog's urins sample is positive by DFM (Nandini et al., 2014). In another study, Leptospires are detected in one out of 27 dog's urine samples by DFM (Rojas et al., 2010). DFM requires high experienced professionals, approximately $10^{4}$ to $10^{5}$ Leptospires/ml urine are necessary for one Leptospira to be visible under DFM (Mythri, 2015). The excretion of Leptospires in urine is intermittent which lowers Leptospires concentration (Budihal and Perwez, 2014).

However, in a previous study, Leptospires are demonestrated in urine samples of two adult dogs suffered from fever, deep colored urine and jaundice by DFM. The study reports that, DFM is a useful method for early diagnosis of leptospirosis (Saritha et al., 2016). DFM is a rapid, easy, reliable and cost effective test for diagnosis of leptospirosis in dogs' urine at field level (Ananda et al., 2008; Rajamani et al., 2016).

Here, Leptospires were detected in urine smears stained by Fontana Method as long, thin, brownish black spirochaetes against yellow background. This is in agreement with previous studies by (Rodríguez et al., 2013; Gunasekara et al., 2017).

In this study, the positive cattle urine samples by Fontana Method were, 44 out of $97(45.4 \%)$. This is in accordance with previous studies by (Badran et al., 2010; Ajaj and Farwachi, 2013). 
In dogs, the positive results of Fontana Method were, 10 out of $12(83.3 \%)$ and 3 out of $6(50.0 \%)$ urine samples of adult dogs and puppies, respectively. The total number of positive urine samples was 13 out of 18 (72.2\%). This is in agreement with a previous study by (Badran et al., 2010).

These results indicated that, the Fontana Method is an easy, rapid and cost effective test for detection of Leptospires in cattle and dogs' urine, which can be used in laboratories, where DFM is unavailable (Yesilmen et al., 2012; Gunasekara et al., 2017). Fontana Method has higher sensitivity when compared with DFM (Rodríguez et al., 2013).

In our study, PCR targeting (23S rDNA) gene of Leptospira was used for accurate confirmation of the results obtained by DFM and Fontana Method. This is in accordance with a previous study, in which, Leptospires are detected in a calf urine by using DFM, and PCR is used for confirmation of the result (Salgado et al., 2015). Leptospires are detected in the urine of carrier animals with a highly detection limit by PCR (Yesilmen et al., 2012).

In case of dogs, PCR was done on three urine samples including one positive and two negatives. Fragments of Leptospiral DNA appeared in the urine sample that was previously positive by both DFM and Fontana Method, while the two negative urine samples were also negative by PCR.

In contrast, Leptospires were detected in (1\%) apparently healthy dogs. This was explained by the low concentrations of Leptospires in the urine of chronically infected dogs, which is below the detection threshold of PCR. However, only one positive animal detected by PCR may has a significant role in contamination of the environment (Latosinski et al., 2018).
PCR is an important, rapid and highly sensitive diagnostic test for the direct detection of Leptospiral DNA in clinical samples (Hernández-Rodríguez et al., 2011). It is a more sensitive than other direct diagnostic methods, such as isolation, immunofluorescence and DFM (Hamond et al., 2014; Pinna et al., 2018). So PCR is recommended as a supplementary test with other diagnostic tests for diagnosis of leptospirosis (Khamesipour et al., 2014).

A trial for treatment of 15 diseased cattle resulted in health improvement and reduction in the severity of clinical signs of leptospirosis from the second day of treatment with Dihydrostreptomycin, Oxytetracycline and Amoxicillin. This in agreement with (Badran et al., 2010). In another study in India, a diseased cow with flabby udder and bloody milk was treated successfully with streptopenicillin (Saravanan et al., 2016).

In contrast, a previous study in Egypt, failed to control leptospirosis in diseased sheep with a combination of Procaine Penicillin and Dihydrostreptomycin and new cases appeared. However, the diseased sheep recovered from leptospirosis after treatment with long-acting Tetracycline. This study recommends Tetracycline as an anti-leptospiral drug (Hatem and Samir, 2014). However, It is recommended to treat cattle as soon as possible after appearance of clinical sings and it is preferable to treat them with dihydrostreptomycin or oxytetracyclines (Adugna, 2016). Amoxicillin (or penicillin), and tetracyclines are successfully used for the treatment of leptospirosis (Gazyagci et al., 2010); and no acquired antibiotic resistance was frequently reported in Leptospira (Goarant, 2016; Correia et al., 2018).

\section{CONCLUSION}

Leptospirosis was detected directly in cattle and dogs' urine by DFM and Fontana Methods. 
DFM is a rapid and easy test for diagnosis of leptospirosis at field level but it lacks sensitivity and specificity, requires highly experienced personnel, and higher count of bacteria in the urine sample to be visible. While Fontana Technique has higher sensitivity, it is an inexpensive method requiring light microscope, which is available in any laboratory. PCR is an accurate and effective diagnostic test, which can be used for confirmation of the results because of its higher sensitivity and specificity. Finally, Bovine leptospirosis was treated successfully by Dihydrostreptomycin, Oxytetracycline and Amoxicillin.

\section{REFERENCES}

Ajaj, E.A., Farwachi, M.I.A., 2013. Detection of bovine leptospirosis using different conventional laboratory tests in nineveh province, Iraq. Journal of Animal Health and Production 1, $32-35$.

Ananda, K.J., Suryananarayana, T., Prathish, P.R., Sharda, R., D'Souza, P.E., 2008. Diagnosis and treatment of leptospirosis in a dog - A Case report. Veterinary World 1, 278-279.

Badran, M.A.M., Abdel Hamid, Y.M., ElBalkemy, F.A.M., Saad, M.A.M., 2010. Studies on some infectious diseases causing bloody urine in cattle. Thesis, $\mathrm{PhD}$ (infectious diseases), Cairo University, Egypt.

Brown, P.D., Gravekamp, C., Carrington, D.G., van de Kemp, H., Hartskeerl, R.A., Edwards, C.N., Everard, C.O., Terpstra, W.J., Levett, P.N., 1995. Evaluation of the polymerase chain reaction for early diagnosis of leptospirosis. Journal of medical microbiology 43, 110-114.

Budihal, S.V., Perwez, K., 2014. Leptospirosis diagnosis: competancy of various laboratory tests. Journal of clinical and diagnostic research 8, 199-202.
Carmona-Gasca, C.A., Leon Lara, L., Castillo, L., Manuel Ramírez-Ortega, J., Ko, A., Luna-Palomera, C., de la PeñaMoctezuma, A., 2011. Detection of Leptospira santarosai and L. kirschneri in cattle: New isolates with potential impact in bovine production and public health, Veterinaria Mexico 42, 277-288.

Constable, P., Hinchcliff, K.W., Done, S., Gruenberg, W., 2017. Veterinary Medicine 11th Edition: A textbook of the diseases of cattle, horses, sheep, pigs and goats. W. B. Saunders Co. Ltd. London, 2308.

Dehkordi, A.J., Shahbazkia, H., Ronagh, N., 2011. Evaluation of pathogenic serovars of Leptospira interrogans in dairy cattle herds of Shahrekord by PCR. Iranian journal of microbiology 3, 135-139.

Ellis, W.A., 2015. Animal leptospirosis. Current topics in microbiology and immunology 387, 99-137.

Goarant, C., 2016. Leptospirosis: risk factors and management challenges in developing countries. Research and reports in tropical medicine 7, 49-62.

Greene, C.E., Millar, M.A., Brown, C.A., 1998. Leptospirosis. In: Infectious diseases of the dog and cat. (2nd Edn). WB Saunders, Philadelphia, 273-281.

Grooms, D.L., 2006. Reproductive losses caused by bovine viral diarrhea virus and leptospirosis. Theriogenology 66, 624-628.

Gunasekara, C., Sumaiha, F., K. S. Damayanthi, M., Weerasekera, M., Fernando, N., 2017. Utility of a modified silver staining technique for detection of Leptospira. Sri Lankan Journal of Infectious Diseases 7, 85-91.

Hamond, C., Pinna, A., Martins, G., Lilenbaum, W., 2014. The role of leptospirosis in reproductive disorders 
in horses. Tropical animal health and production $46,1-10$.

Hatem, M.E., Samir, A., 2014. The first recorded epidemic of leptospirosis in sheep in Egypt. Revue scientifique et technique (International Office of Epizootics) 33, 889-892.

Hernández-Rodríguez, P., A Díaz, C., A Dalmau, E., M Quintero, G., 2011. A comparison between polymerase chain reaction (PCR) and traditional techniques for the diagnosis of leptospirosis in bovines. Journal of microbiological methods 84, 1-7.

Kelly, R., 1986. Veterinary clinical diagnosis.4th edition. Bailliere Tindal, London.

Khamesipour, F., Doosti, A., Emadi, M.F., Awosile, B., 2014. Detection of Brucella sp. and Leptospira sp. in dogs using conventional polymerase chain reaction. The Journal of National Veterinary Research Institute in Pulawy 58, 527-531.

Klaasen, H.L.E., Adler, B., 2015. Recent advances in canine leptospirosis: focus on vaccine development. Veterinary medicine (Auckland, N.Z.) 6, 245-260.

Krishna, S.V., Siju Joseph, R, A., Mini, M., 2012. Evaluation of dark field microscopy, isolation and microscopic agglutination test for the diagnosis of canine leptospirosis. International Journal of Pharmacy and Biological Sciences 2, 85-89.

Lather, D., Saxena, V., Mishra, S.K., 2009. Leptospirosis in a dog: A case Report. Haryana Veterinarian 48, 110-111.

Latosinski, G.S., Fornazari, F., Babboni, S.D., Caffaro, K., Paes, A.C., Langoni, H., 2018. Serological and molecular detection of Leptospira spp in dogs. Revista da Sociedade Brasileira de Medicina Tropical 51, 364-367.
Mythri, B.A., 2015. Laboratory diagnosis of leptospirosis: A review. Journal of Evolution of Medical and Dental Sciences 4, 8759-8769.

Nandini, M.K., Ramesh, P.T., Yathiraj, S., Anilkumar, M.C., Narayan Swamy, M., Honnappa, T.G., 2014. Studies on epidemiological, clinical and molecular diagnosis of leptospirosis in dogs. Thesis, $\mathrm{PhD}$ veterinary medicine Karnataka Veterinary, Animal and Fisheries Sciences University, India.

Pinna, M.H., Martins, G., Loureiro, A.P., Lilenbaum, W., 2018. Detection of bovine carriers of Leptospira by serological, bacteriological, and molecular tools. Tropical animal health and production 50, 883-888.

Quinn, P.J., Markey, B.K., Leonard, F.C., Hartigan, P., Fanning, S., FitzpatrickE. S., 2011. Veterinary microbiology and microbial disease, 2nd Edition. 928.

Rajamani, S.S., Krishnan, S., Radhakrishnan, S., 2016. Efficacy of dark field microscopy and IgM-ELISA in the detection of leptospirosis, Journal of Evidence Based Medicine and Healthcare 3, 3542-3546.

Rodríguez, I., Rodríguez, I., Fernández, C., Rodríguez, J.E., Cantillo, J., 2013. Detection of Leptospires from infected urine and tissue samples in vitro by modified Fontana silver stain. Jornal Brasileiro de Patologia e Medicina Laboratorial 49, 39-45.

Rojas, P., Monahan, A., Schuller, S., Miller, I., K Markey, B., E Nally, J., 2010. Detection and quantification of Leptospires in urine of dogs: A maintenance host for the zoonotic disease leptospirosis. European journal of clinical microbiology \& infectious diseases 29, 1305-1309.

Romero-Vivas, C.M., Cuello-Perez, M., 
Agudelo-Florez, P., Thiry, D., Levett, P.N., Falconar, A.K., 2013. Crosssectional study of Leptospira seroprevalence in humans, rats, mice, and dogs in a main tropical sea-port city. The American journal of tropical medicine and hygiene $88,178-183$.

Safiullah, S.A., Abu Saleh, A., Munwar, S., 2009. Laboratory methods for diagnosing leptospirosis: A Review. Bangladesh Journal of Medical Microbiology 3, 39-43.

Sakhaee, E., Abdollahpour, G., Bolourchi, M., Tabatabayi, H., Sattari Tabrizi, S., 2007. Serologic and bacteriologic diagnosis of bovine leptospirosis in Tehran suburb dairy farms. Iranian Journal of Veterinary Research 8, 325-332.

Salgado, M., Otto, B., Moroni, M., Sandoval, E., Reinhardt, G., Boqvist, S., Encina, C., Munoz-Zanzi, C., 2015. Isolation of Leptospira interrogans serovar Hardjoprajitno from a calf with clinical leptospirosis in Chile. BMC veterinary research 11: 66, 1-4.

Saravanan, S., Palanivel, K.M., Sathyabama, T., Asokan, S., 2016. Flabby udder mastitis due to leptospirosis in a cow. The Indian Veterinary Journal 93, 65-66.

Saritha, G., Haritha, G., Kumari, K.N., 2016. Clinical diagnosis and treatment of leptospirosis in two dogs. International Journal of Veterinary Science 5, 186188.

Shafighi, T., Abdollahpour, G., Salehi, Z., Tajbakhsh, H., 2010. Serological and bacteriological study of leptospirosis in slaughtered cattle in North of Iran (Rasht). African journal of microbiology research 4, 2118-2121.

Sykes, J.E., Hartmann, K., Lunn, K.F., Moore, G.E., Stoddard, R.A., Goldstein, R.E., 2011. 2010 ACVIM small animal consensus statement on leptospirosis: diagnosis, epidemiology, treatment, and prevention. Journal of veterinary internal medicine 25, 1-13.

Woo, T.H., Patel, B.K., Smythe, L.D., Symonds, M.L., Norris, M.A., Dohnt, M.F., 1997. Identification of pathogenic Leptospira genospecies by continuous monitoring of fluorogenic hybridization probes during rapid-cycle PCR. Journal of clinical microbiology, 35, 3140-3146.

Yesilmen, S., Arserim, N.B., Isik, N., Icen, H., 2012. Determination of prevalence of pathogenic Leptospira spp. by RealTime PCR in cattle in Diyarbakır. Yüzüncü y1l Üniversitesi Veteriner Fakültesi Dergisi 23137 - 139.

Zacarias, F.G., Vasconcellos, S.A., Anzai, E.K., Giraldi, N., de Freitas, J.C., Hartskeerl, R., 2008. Isolation of Leptospira serovars canicola and copenhageni from cattle urine in the state of Parana, Brazil. Brazilian journal of microbiology 39, 744-748. 